This is an accepted manuscript. The published version may differ from it. Please cite as: Singh, M., Acerbi, A., Caldwell, C., Danchin, É., Isabel, G., Molleman, L., Scott-Phillips, T., Tamariz, M., Van den Berg, P., van Leeuwen, J. C., \& Derex, M. (forthcoming) Beyond social learning. Philosophical Transactions of the Royal Society B: Biological Sciences. 10.1098/rstb.2020.0050

\title{
Beyond social learning
}

Manvir Singh*1, Alberto Acerbi ${ }^{2}$, Christine Caldwell ${ }^{3}$, Étienne Danchin ${ }^{4}$, Guillaume Isabel ${ }^{5}$, Lucas Molleman ${ }^{6}$, Thom Scott-Phillips ${ }^{7}$, Monica Tamariz ${ }^{8}$, Pieter Van den Berg', Edwin J. C. van Leeuwen

${ }^{1}$ Institute for Advanced Study in Toulouse, Toulouse 31015, France

${ }^{2}$ Center for Culture and Evolution, Brunel University London, Middlesex UB8 3PH, UK

${ }^{3}$ Department of Psychology, University of Stirling, FK9 FLA Stirling, UK

${ }^{4}$ Laboratoire Évolution and Diversité Biologique, Université Fédérale de Toulouse, F-31062 Toulouse cedex 9, France

${ }^{5}$ Centre de Recherches sur la Cognition Animale, Centre de Biologie Intégrative, Université Fédérale de Toulouse, F-31062 Toulouse cedex 9, France

${ }^{6}$ Amsterdam Brain and Cognition, University of Amsterdam, 1018 WT Amsterdam, The Netherlands

${ }^{7}$ Department of Cognitive Science, Central European University, Budapest 1051, Hungary

${ }^{8}$ Department of Psychology, Heriot-Watt University, Edinburgh EH14 4AS, UK

${ }^{9}$ Department of Biology, KU Leuven, B-3000 Leuven, Belgium

${ }^{10}$ Department of Biology, University of Antwerp, 2610 Wilrijk, Belgium

${ }^{10}$ Centre for Research and Conservation, Royal Zoological Society of Antwerp, B 2018 Antwerp, Belgium

*Corresponding authors: manvir.singh@iast.fr; maxime.derex@iast.fr

\begin{abstract}
Cultural evolution requires the social transmission of information. For this reason, scholars have emphasized social learning when explaining how and why culture evolves. Yet cultural evolution results from many mechanisms operating in concert. Here, we argue that the emphasis on social learning has distracted scholars from appreciating both the full range of mechanisms contributing to cultural evolution and how interactions among those mechanisms and other factors affect the output of cultural evolution. We examine understudied mechanisms and other factors and call for a more inclusive program of investigation that probes multiple levels of organization, spanning the neural, cognitive-behavioural, and populational levels. To guide our discussion, we focus on factors involved in three core topics of cultural evolution: the emergence of culture, the emergence of cumulative cultural evolution, and the design of cultural traits. Studying mechanisms across levels can add explanatory power while revealing gaps and misconceptions in our knowledge.
\end{abstract}

Keywords: adaptation, culture, cultural evolution, cumulative culture, mechanism, social learning 


\section{Introduction}

Scholars studying how and why culture evolves have long focused on social learning. This makes sense. For many researchers, culture is socially-learned information [1-3], making social learning central in the emergence of culture and a natural starting point when studying cultural evolution. In line with this focus, scientists aiming to explain the uniqueness of human culture began by asking how social learning differs between humans and our closest relatives [4], inspiring comparative research directed at pinpointing the learning capacities that set humans apart $[5,6]$. Similarly, scientists interested in the origins of cultural adaptations (e.g., igloos, food-processing) began by asking how social learning, when iterated, gives rise to adaptive, cultural evolutionary processes $[7,8]$. This focus has been productive, yielding valuable insights about cultural transmission, cultural adaptation, and capacities that distinguish humans from other primates $[6,9,10]$.

Despite the value of studying social learning-defined here as learning that occurs through the acquisition of information from a social source-the current focus has two major limitations. First, it distracts from other important factors. Growing evidence suggests that many mechanisms aside from social learning contribute to cultural evolution. The emergence of culture hinges not only on social transmission but on cognitive capacities enabling innovation, too. Cumulative cultural evolution depends on high-fidelity transmission, yes, but just as critically on cognitive flexibility and the frequency of interaction between cultural learners. And cultural traditions exhibit features that are crucially shaped by factors such as status asymmetries, biases involved in traits' evaluation, and the distribution of beliefs within groups. We do not deny that social learning is important, nor do we assert that scholars do not appreciate that other mechanisms contribute. Rather, we contend that the focus on social learning may distract from complementary mechanisms that help explain central research foci, such as why some species have culture or how cumulative cultural evolution emerges.

A second limitation of the focus on social learning is that researchers commonly treat it simply as an expressed behaviour, blackboxing underlying mechanisms [9,11]. Blackboxing is, of course, a necessary first step when explaining any behaviour. A researcher trying to explain the spread of prosocial religion might point to its effects on cooperation, abstracting the molecular interactions and neural processes involved in cooperative decision-making. To do otherwise-to consider each molecule or firing neuron-would be unmanageable. But blackboxing also carries risks. In the case of social learning, one problematic consequence is the resulting assumption that different behaviours, such as social and non-social learning, have distinct neurocognitive foundations and thus constitute independently evolving "traits" [12]. A related risk is that ignoring the underpinnings of social learning overlooks the possibility that many learning behaviours may be the products of less specialized cognitive building blocks (see [13] for a similar argument as applied to other apparently derived human abilities). A complete understanding of cultural evolution requires considering mechanisms and other factors ("factors" from here onwards) across levels of organization and appreciating how interactions among factors affect the output of cultural evolution.

Here we review promising and understudied factors contributing to cultural evolution. We organize these into three levels of organization: neural, cognitive/behavioural, and populational (Box 1). Our goal is to identify factors that add explanatory power while revealing 
erroneous assumptions and gaps in our knowledge of how and why culture evolves. We also review the mechanistic underpinnings of social learning to demonstrate how peering into the black box can transform our understanding of culture.

Our aim is not to comprehensively enumerate the factors that affect cultural evolution. Instead, it is to point readers towards overlooked factors while illustrating the value of a multilevel approach. In that vein, we focus three questions that have arguably attracted the most attention in cultural evolutionary research:

1. What explains the emergence of culture?

2. What explains cumulative cultural evolution?

3. What explains the design of cultural traits?

\section{Box 1. Three levels of organization}

We structure our discussion of mechanisms and other factors into three levels of organization:

1. The neural level concerns neurons and their interaction. Neural factors include neurophysiology, the structure of neural networks, and the density of neurons.

2. The cognitive-behavioural level concerns both mental computations and their behavioural outputs. Mental computations include algorithms involved in perception, kin detection, and representations of possibility. Behavioural outputs consist of actions resulting from the interaction between individuals' internal processes and their environment. Although cognition and behaviour are often regarded as distinct levels of organization, we treat them together here because of the difficulty of sometimes isolating mental computations from their behavioural outputs.

3. The populational level concerns features of populations such as size, structure, and density, as well as by traits that only exist at the group-level, such as markers of group identity.

Readers should note three complexities. First, these levels are hierarchically structured. Cognition, for instance, consists of mental computations that emerge from interactions among neurons. Second, there are other levels of organization buried within these three levels. Interactions among neurons, for instance, may give rise to neural networks, whose interaction might in turn manifest as cognition. Finally, a phenomenon at any level can be influenced by entities at both lower and higher levels. Cognitive algorithms are patterned abstractions of neural activity, but they can take as inputs information about population-level variables, such as levels of competition.

\section{Factors contributing to the emergence of culture}

Why do some species have culture, while others do not? Given that culture relies on the social transmission of behaviour, attention has focused on social learning capacities, mostly in vertebrates, but in insects as well $[6,14]$. Yet although culture necessitates social learning, social learning does not necessarily result in culture. For a behaviour to qualify as a cultural tradition, it must be shared by two or more individuals and persist over time [15]. Recognizing this, we here examine social learning at different levels of explanation and consider other factors potentially 
involved in the emergence of culture. We review evidence that species such as bumblebees engage in cultural transmission using general-purpose learning mechanisms. Given that these general learning mechanisms are shared widely among animals - and are likely much more widespread than culture - we consider how capacities aside from social learning, such as memory, innovation, and social interaction, may underlie the emergence of culture.

\subsection{Neural}

Research on neural mechanisms helps specify which faculties are involved when an individual learns from another, resolving whether particular neural specializations are necessary for cultural transmission. Studies of the neurogenetics of social learning among model species where genetic and molecular tools are available show that the neural machinery for social learning overlaps considerably with that of non-social learning and that such machinery exhibits commonalities across taxa. In primates and rodents, social information triggers activity in the same reward pathways involved in non-social learning, such as the ventral striatum and medial prefrontal cortex [16-18]. Work on rodents and humans suggest that, at least when socially learning about threats, both social and non-social information are processed in a common value-representation circuits [19]. Similarly, in Drosopbila, the neurotransmitters [20] and functions of neural structures [21] involved in social learning are the same as those involved in non-social learning. Research indicates that these structures play a role in learning, memory, and reward in vertebrates, suggesting a phylogenetically ancient origin [20,22]. Although social learning also incorporates information that non-social learning does not $[19,23]$, the capacity to learn from others emerges from mechanisms designed for learning more generally [19].

Among the neural mechanisms of learning, those underlying long-term memory are critical because they allow social information to be encoded [24]. Despite their importance, however, such mechanisms remain largely overlooked in the study of cultural transmission. As biologists recognize, long-term memory must involve the fine-tuning of gene expression, which can in turn involve epigenetic change, making it a promising direction of future study $[25,26]$. Although the mechanistic understanding of memory formation remains superficial, research has shown that blocking major epigenetic routes interferes with memory formation. In rats, for instance, the inhibition of the DNA methyltransferases fully blocks contextual fear conditioning, as well as memory formation, following the rapid methylation of memory suppressor genes and demethylation of memory promoting genes in a highly dynamic way in the hippocampus [27]. Studying the epigenetic basis of memory will help clarify its mechanistic basis and provide insight into the foundations of learning and culture more broadly.

In short, the striking similarities of mechanistic pathways among vertebrates and invertebrates suggest that the basic mechanisms of culture are ancestral, and that culture may be far more common in animals than previously suspected. Insofar as non-cultural species have general-purpose learning mechanisms, and therefore some form of social learning, explaining the emergence of culture will require examining capacities aside from social learning.

\subsection{Cognitive-behavioural}

Research on cognitive-behavioural mechanisms further demonstrates that social learning can emerge from general capacities serving to acquire information, regardless of whether that 
information comes from a social source [28]. Consider bumblebees, which copy the foraging preferences of other hive members [29]. Researchers studying this behaviour have found evidence that bumblebees engage in second-order associative learning. In the same way that Pavlov's dog associated a metronome tick with food, bumblebees seem to learn to associate the presence of conspecifics with rewards. And just as Pavlov's dog could then learn secondary associations (e.g., salivating at a black box associated with a metronome tick), bumblebees may learn stimuli associated with conspecifics because they are reliable indicators of rewards [30]. Researchers have provided support for this explanation using a series of ingenious experiments. They have shown that naïve individuals do not yet treat conspecifics as indications of rewards [31], and that reducing the reliability of social information [32] and associating conspecifics with bitter substances [31] lead bumblebees to no longer use social information and to avoid stimuli associated with conspecifics, respectively. Moreover, there is no difference between how trained bumblebees use information from heterospecifics and how they use information from conspecifics [33]. Bumblebees socially learn by using general learning mechanisms that are likely widely shared among animals.

If social learning can occur with widespread, general learning mechanisms, then which additional capacities are needed for culture? One potentially crucial enabler of culture is the capacity to innovate, which generates cultural variation [34,35]. Although scholars have considered innovation when explaining cumulative cultural evolution [36,37], the capacities underlying innovation have gone largely overlooked in explaining why some species have traditions. The importance of innovation has been demonstrated again with bumblebees. Alem et al. [38] found that a technique on a string-pulling task could diffuse from a knowledgeable bumblebee to the majority of a colony's foragers. Yet they also found that virtually no individuals could innovate the technique on their own. Bumblebees, like Drosophila [24], have the abilities necessary to maintain and transmit culture, but it remains unclear whether bumblebees can generate enough cultural variation. An animal's capacity to innovate seems to hinge on factors such as motor variability, persistence, exploration, analogical reasoning, neophilia, and learning speed [39-42]. Given that species vary greatly in their tendency to innovate [43,44], the underlying capacities for innovation may be critical for determining whether a species has culture.

\subsection{Populational}

Population-level variables are usually invoked to explain cultural complexity and aspects of cultural form (see sections 3 and 4). But they are also likely key for whether a species has culture in the first place. The capacity to learn socially has been observed in supposedly solitary species such as the common octopus [45] and the red-footed tortoise [46]. If, as Heyes [12] suspects, conspecifics interact infrequently in these species, it is unlikely that they have culture. For a cultural tradition to persist, individuals need to interact frequently enough for cultural traits to transmit. Individuals should be tolerant and sufficiently gregarious, both cognitive-behavioural tendencies that, in turn, have population-level effects [47]. In many cases, interaction alone does not appear sufficient. Experiments with humans suggest that multiple exposures are necessary for a trait to remain stable $[48,49]$, while theoretical work suggests that, under many conditions, uniparental transmission is not sufficient to maintain culture [50]. Moreover, given that many, if not all, cultural traits are only expressed in particular circumstances, such as foraging, mate 
choice, and food processing [51], the likelihood that a species exhibits cultural traditions should vary with the number of contexts in which conspecifics interact.

\section{Factors contributing to cumulative cultural evolution}

While the capacity for culture is present across a broad taxonomic range, the capacity for cumulative culture (i.e. the repeated modification and social learning of cultural traits over successive generations [52]) seems to be absent, or at least uncommon, in non-human species. Recent research suggests that some non-human animals may exhibit simple forms of cumulative cultural evolution (CCE) [53-55], but the diversity and complexity of human cumulative culture remain unparalleled [10].

Despite attempts to identify the mechanisms responsible for cumulative culture (e.g., [56-58]), there is still no consensus on what makes human culture so distinctive. Because CCE only operates when information is passed socially, scholarly attention has focused on capacities that promote informational stability. At the individual level, these include social learning abilities that support high-fidelity transmission, such as imitation and teaching [59,60]. At the group level, scholars have stressed the role of the size of the population that shares social information in buffering the risk of losing cultural traits [61]. Still, theoretical work shows that factors that support the production of new traits are no less important than factors that promote their maintenance to explain CCE [37]. Furthermore, mechanisms that support high-fidelity transmission only become important when individuals are willing to abandon previous behaviours. Explaining CCE requires recognizing the explanatory role of factors that contribute not only to the maintenance of cultural traits but to their production and spread, as well.

\subsection{Neural}

Evolutionary neuroscience can help explain cumulative cultural evolution by uncovering the human neural mechanisms that promote the production, spread and maintenance of cumulative culture [62]. Davis et al., for instance, attributed the existence of CCE partly to humans' unique behavioural flexibility, which allows individuals to relinquish existing behaviours to adopt more efficient ones [63]. The neural underpinnings of this flexibility are still unclear [13], but recent research has identified one potential mechanism. Cross-species investigations tracking the activity of single neurons indicate that human brains trade off robustness (in terms of higher speed of response and increased reliability) for greater efficiency in information processing. This lower robustness promotes the flexible learning of new tasks and adaptation to new conditions although at the cost of slower and less reliable production of behavioural responses [64].

Cultural evolutionary researchers have also suggested that creativity and innovation might enable cumulative cultural evolution ([36,37]; see also [34]). Indeed, the modification of cultural traits includes what researchers call "guided variation", wherein human intention and intelligence produce cultural variants that are on average culturally more successful than would be expected by chance [7]. Evolutionary neuroscience research allows us to pinpoint the precise faculties that might underpin the production of guided variation. For instance, comparative studies have revealed that humans possess unusually large brains (both in terms of absolute and relative size) and that absolute and relative brain sizes correlate with innovation frequency in primates [44]. 
Furthermore, human brains contain more cortical neurons than those of any other mammals, which allows more neuronal specialization and increases the number of computational levels involved in information processing, decision-making, and information storage $[65,66]$. These examples demonstrate how considering the neural basis of human uniqueness might help explain our capacity for elaborate cumulative cultural evolution.

\subsection{Cognitive-behavioural}

Humans exhibit several cognitive-behavioural capacities aside from social learning that allow the propagation of complex cultural traits. One example is the capacity for future thinking and mental time travel [57], which may be limited to humans [67]. Mental time travel is potentially important because acquiring complex culture can be costly. Stout [68] observed that an apprenticeship in adze-making in the New Guinean village of Langda began at the age of 12-13 and lasted for several years, although "it might take ten years or more for the highest level of skill to be achieved." Ache hunter-gatherers do not peak in their marksmanship skills until the age of 40 [69]. A sensitivity to short-term self-interest might prevent individuals from investing in learning behaviours that confer benefits later in life. By making salient the long-term benefits, mentally travelling forward in time might make individuals more tolerant of learning costs and more willing to adopt unfamiliar behaviours.

The propagation of cultural traits that are not immediately beneficial might be further supported by our comparatively greater motivation to attend to sources of social information (e.g., [70]). Indeed, social learning abilities only become important when individuals are motivated to pay attention to what other are doing. Evidence for the role of this tendency in the propagation of cultural traits comes from comparative experiments conducted with humans and other apes. Compared to chimpanzees, for instance, children are more likely to solve problems which they have failed to solve for themselves upon exposure to social information demonstrating the solution [71-73]. Thus, human motivation towards social information may have the effect of allowing rapid acquisition of effective techniques that are difficult to innovate from scratch.

Importantly, this tendency might be connected to other well-developed human capacities, such as theory of mind and metacognition, which allow humans to recognize intention behind another's behaviour and infer utility from social demonstration [74].

Finally, cumulative cultural evolution should be favored by humans' communication, a capacity that remains understudied in the cultural evolutionary literature. Humans communicate in a way that is, if not unique to our species, certainly distinctive [75,76]: Human communication is not just intentional, it is overtly intentional. Through behaviours such as eye contact, motherese, stylization, and exaggeration, communicators show audiences that an action is done for the audience - and this 'for-ness' helps audiences interpret the stimuli $[77,78]$. Human infants can differentiate among behaviours produced (i) accidentally, (ii) intentionally but not communicatively (i.e. without overt intentionality), and (iii) communicatively (i.e. in an overtly intentional way) [79-84]. Overtly intentional communication (and particularly language) allows potential learners to query what they do not understand, and allows experienced individuals to explain, justify, and instruct, as appropriate to the needs of the learner $[85,86]$. Communication, like attention towards social stimuli, may enable cumulative cultural evolution by promoting the opportunity for social learning, as well as the fidelity of transmission. 


\subsection{Populational}

The population-level variables most often invoked to explain cumulative cultural evolution are population size and structure. According to experimental and theoretical work, population size is important because the risk of losing cultural information varies with the number of potential demonstrators [87]. As the number of demonstrators declines, the risk of losing cultural information increases. Meanwhile, population structure is important because individuals' opportunity for innovation varies with the cultural diversity they encounter [88-90]. In studying these mechanisms, researchers typically assume that individuals have unconstrained access to others' solutions. Yet in more realistic situations, skilled demonstrators might have no interest in providing useful information to unrelated individuals [91]. This limitation suggests that more attention should be paid to the formation of social links that are conducive to cultural transmission. A recent study in hunter-gatherer populations revealed that individuals invest early in their childhood in a few close friends and that friendship facilitates the sharing of social information during adulthood [92]. Other studies have reported that social links are more likely to form between people who share similar traits [93,94]. Group-level traits, such as stylistic markers of group identity, might thus promote CCE by extending the size of the social network through which cultural information can flow. Finally, group-level factors, such as the intensity of group-level competition, might influence individuals' propensity to share information. Indeed, experimental work shows that demonstrators set lower informational access costs (the costs that potential learners must pay in order to access the demonstrators' information) when their groups engage in between-group competition [95]. In these examples, population-level mechanisms shaping cumulative cultural evolution stem from individuals' propensities to connect and share information. A better understanding of these mechanisms will help clarify how individual-level interactions produce population-level dynamics, resulting in the emergence of cumulative cultural evolution.

\section{Factors contributing to the design of cultural traits}

Why do cultural traits exhibit the features that they do? As with research on culture and cumulative cultural evolution, research on the factors responsible for the design of cultural traits grew out of a focus on social learning. Researchers interested in explaining adaptive culturevariants that allow individuals to better exploit their environments-began a fruitful tradition of building theoretical models in which iterated social learning gives rise to emergent cultural evolutionary processes $[7,96]$. These include models in which success- and prestige-biased learning drives the selection of variants that promote prestige, health, and other indicators of success, and in which conformity and other learning biases create enduring group-level differences, allowing for selection among equilibria (cultural group selection). Of course, researchers appreciate that other forces shape cultural form. Boyd and Richerson acknowledged the role of content biases, while proponents of Cultural Attraction Theory have long advocated that features of our cognitive architecture favor some variants over others $[97,98]$. Nevertheless, we here propose that research on cultural form will benefit from considering factors beyond the most commonly cited cultural evolutionary processes. We highlight the value of a multilevel 
approach and the advantages of incorporating insights from fields such as economics and political science, which have long aimed to explain the form of institutions specifically [99-101].

\subsection{Neural}

Examining neural underpinnings can help explain why cultural traits exhibit the features that they do in at least two ways. First, basic neural mechanics constrain the design of cultural traits. For instance, Nieder [102] argues that neuronal mechanisms of estimating number, which are products of a phylogenetic heritage, contribute to the relative ease of discriminating numbers of low values (e.g., 1 and 2) over discriminating numbers of higher values (e.g., 783 and 784). This, in turn, seems to shape numbering systems, biasing them to discriminate among low numbers but not high ones (e.g., low-limit number systems such as "one", "two", "many") [103].

Studying neural underpinnings can also illuminate the structure of cognitive systems, helping explain how our mental computational systems bias which representations we adopt. An example is mind-body dualism. Researchers hypothesize that mind-body dualism, manifesting as beliefs in souls, ghosts, zombies, and possession, results from a computational division between processing mental information and processing physical information [104]. Although psychological experiments can indirectly indicate whether information of the two kinds is processed separately $[105,106]$, another test involves examining where in the brain that information is represented. In that vein, research now suggests a division between those brain areas or networks specialized for social cognition and those specialized for physical cognition [107]. Notably, the value here of examining neural activity is that it sheds light on the functioning of cognitive mechanisms. Studying a cognitive mechanism at the neural level allows us to better characterize the mechanism's behaviour and its effects on cultural design (see a similar approach in the field of neuroaesthetics: [108]).

\subsection{Cognitive-behavioural}

Researchers have made major progress applying cognitive science to explain the design of cultural traits. Many cognitive and social scientists, for instance, ask how reliably developing features of human psychology predispose people to find certain variants more memorable, believable, entertaining, attention-grabbing, or apparently useful [97,98,109-112]. Such researchers have used attentional biases to explain portraits [113], epistemological mechanisms to explain divination [114], mechanisms for representing agents to explain gods [115], suites of automatic inferential systems to explain economic beliefs [116], the mechanics of emotion to explain story [117-119], the psychology of outrage and paranoia to explain witchcraft [120], and systems for identifying causality and conceptualizing humanness to explain shamanism [121]. Researchers have also found that people preferentially remember and transmit negative information [122], threat-related information [123], elements eliciting disgust [124], and information about social interactions and relationships [125,126], helping explain the form of news [127,128], fiction $[129,130]$ (although see [131]), urban legends [126], and online misinformation [132].

As this diversity demonstrates, studying psychological systems is potent for understanding how features of human cognition fashion culture. But scholars have overlooked at least one additional set of capacities: the subjective psychological criteria involved in evaluations $[133,134]$. Evaluation crucially contributes to the development of much of culture. People often 
selectively copy and retain variants they evaluate as serving their goals, over time resulting in increasingly compelling cultural traditions. Still, mechanisms for evaluating causal relationships can be erroneous, resulting in ineffective practices. In a well-known example, scouts and managers of baseball teams evaluated players on the basis of easy-to-observe traits, while undervaluing traits that seemed out of a player's control (e.g., whether a pitcher threw bad pitches at them) [135]. This, in turn, led to systematic inefficiencies in the design of teams. Similarly, humans are endowed with cognitive mechanisms for evaluating whether some technology produces a desired end. However, biases in these mechanisms predispose us to note erroneous causal relationships, such that acting on one object (such as a voodoo doll) is thought to affect the target it resembles (a rival) [136]. Magical practices seem to evolve because they are subjectively evaluated as producing a desired end, even though they are ultimately ineffective [137]. Characterizing the psychological mechanisms involved in evaluating efficacy will help explain the evolution of functional complexity, systematic inefficiencies, and elaborate but ineffective technologies.

\subsection{Populational}

There are many population-level properties aside from population size or structure that shape culture yet remain underexplored in the cultural evolution literature. Perhaps the two most important are power and competition.

Power is the capacity of a party to change other parties' behaviour [138]. There are many ways in which distributions of power can shape culture, but the most important is when individuals compete to institute and maintain self-serving rules $[139,140]$. The form of these rules is frequently determined by the parties' relative abilities to enforce their preferences. Distributions of power explain, among many other outcomes, food taboos in small-scale societies, rules for how children should treat fathers, institutions of redistribution throughout Polynesia, and the political institutions of colonial powers and their local inheritors around the world $[139,141,142]$. Of course, just as distributions of power shape institutions, institutions can shape distributions of power [142]. Still, power leaves such defining marks on institutions and practices that it has become the primary lens through which scholars in fields such as Marxist and feminist anthropology analyze culture. Although cultural evolutionary scholars have begun to consider power when explaining practices such as religion [143] and human sacrifice [144], and although some have considered it as an outcome of interest [145], it should be considered when explaining any tradition that involves conflicts of interest among competing parties.

Another population-level characteristic that partly determines cultural form is the intensity of competition, whether between individuals or groups. Competition determines how much competing parties invest in services or signals, driving variation in the elaborateness of culture. In markets, higher competition among service providers drives up the quality of services, transforming products including cars, supermarkets, and even the trance performances of shamans $[121,146,147]$. Increased status competition, which may be driven by rising inequality, is correlated with higher investments in signaling, presumably as individuals want to discriminate themselves from competitors [148]. This manifests in increasingly showy signs of wealth and status, transforming practices ranging from potlatches [149] to female adornment on social media [148]. 
Population-level mechanisms aside from power and competition shape culture, as well. One example is what researchers call "common knowledge"-roughly, recursive, shared beliefs that enable coordination [150]. Without channels facilitating widespread coordination, populations often sustain suboptimal practices, even when the majority of individuals prefer to change them. Social scientists posit that such "pluralistic ignorance" has maintained suboptimal norms and institutions including drinking behaviour on US college campuses [151] and restricted female labor force participation in Saudi Arabia [152].

\section{Conclusion}

Explanations for the existence, accumulation, and design of cultural traditions benefit from a perspective that is both broad and deep, that both considers interactions among a web of factors and clarifies their contribution by probing their deeper workings. Not only does such a perspective reveal that a more diverse set of factors shapes culture, but it also suggests that explanations currently regarded as alternatives are, in fact, complimentary.

We reviewed potential factors at the neural, cognitive-behavioural, and populational levels. But other levels are relevant too, including the genetic, epigenetic, and inter-populational levels. Moreover, cultural evolution can be influenced and constrained by physiology and existing cultural traditions, as well as the biotic and abiotic environment. For instance, explaining cumulative culture may require not only specifying behavioural differences but anatomical ones, as well. Since Darwin, theorists have hypothesized that unique features of human anatomy, especially bipedalism, were key for setting the evolutionary stage for our greater reliance on tools and cultural knowledge [153]; cultural evolutionists may benefit from considering such anatomical pre-adaptations. Similarly, explaining a cultural artifact like a spear demands considering not only the transmission processes allowing manufacturing knowledge to evolve, but also the anatomy of the primate hand, existing tools and techniques for procuring spearmaterials, and the animals spear-makers intend to hunt.

We have proposed many directions of future research in this paper; among the most important is the development of studies on culture in non-human animals. The lack of data on culture in animals likely stems from researchers only recently expanding investigations beyond charismatic and supposedly intelligent vertebrates. After all, we now have surprising evidence that even insects may have culture [24,38], suggesting that culture is phylogenetically ancient, present among ancestors that lived hundreds of millions of years ago. This constitutes a stimulating challenge for the study of the foundations of cultural evolution.

\section{Acknowledgements}

M.S. and M.D. acknowledge IAST funding from ANR under grant ANR-17-EURE-0010 (Investissements d'Avenir program). C.C. was supported by a European Research Council (ERC) Consolidator Grant (No. 648841 RATCHETCOG). T.S.P. was supported by the European Research Council, under the European Union's Seventh Framework Programme (FP7/2007-2013)/ERC grant agreement no. 609819 (Somics project). M.D. received funding from the European Union's Horizon 2020 Research and Innovation Programme (under Marie Sklodowska-Curie grant agreement number 748310). 


\section{References}

1. Mesoudi A. 2011 Cultural Evolution: How Darwinian Theory Can Explain Human Culture and Synthesize the Social Sciences. University of Chicago Press.

2. Richerson PJ, Boyd R. 2008 Not by genes alone: How culture transformed buman evolution. Chicago: University of Chicago Press.

3. Rendell L, Whitehead H. 2001 Culture in whales and dolphins. Behav. Brain Sci. 24, 309-382. (doi:10.1016/B978-0-12-373553-9.00068-7)

4. Tomasello M, Kruger AC, Ratner HH. 1993 Cultural learning. Behav. Brain Sci. 16, 495-511.

5. Whiten A, McGuigan N, Marshall-Pescini S, Hopper LM. 2009 Emulation, imitation, over-imitation and the scope of culture for child and chimpanzee. Pbilos. Trans. R. Soc. Lond. B. Biol. Sci. 364, 2417-28. (doi:10.1098/rstb.2009.0069)

6. Whiten A. 2017 Social learning and culture in child and chimpanzee. Annu. Rev. Psychol. 68, 129-154. (doi:10.1146/annurev-psych-010416-044108)

7. Boyd R, Richerson PJ. 1985 Culture and the evolutionary process. Chicago: University of Chicago Press.

8. Cavalli-Sforza LL, Feldman MW. 1981 Cultural transmission and evolution: A quantitative approach. Princeton University Press.

9. Kendal RL, Boogert NJ, Rendell L, Laland KN, Webster M, Jones PL. 2018 Social Learning Strategies: Bridge-Building between Fields. Trends Cogn. Sci. 22, 651-665. (doi:10.1016/j.tics.2018.04.003)

10. Henrich J. 2015 The secret of our success: How culture is driving human evolution, domesticating our species, and making us smarter. Princeton, NJ: Princeton University Press.

11. Heyes C. 2016 Blackboxing: Social learning strategies and cultural evolution. Philos. Trans. R. Soc. B Biol. Sci. 371. (doi:10.1098/rstb.2015.0369)

12. Heyes C. 2012 What's social about social learning? J. Comp. Psychol. 126, 193-202. (doi:10.1037/a0025180)

13. Rosati AG. 2017 Chimpanzee cognition and the roots of the human mind. In Chimpanzees and human evolution, pp. 703-745. Harvard University Press.

14. Laland K, Evans C. 2017 Animal social learning, culture, and tradition. In APA Handbook of Comparative Psychology, pp. 441-460.

15. Whiten A, Hinde R a, Laland KN, Stringer CB. 2011 Culture evolves. Pbilos. Trans. R. Soc. Lond. B. Biol. Sci. 366, 938-48. (doi:10.1098/rstb.2010.0372)

16. Dölen G, Darvishzadeh A, Huang KW, Malenka RC. 2013 Social reward requires coordinated activity of nucleus accumbens oxytocin and serotonin. Nature 501, 179-184. (doi:10.1038/nature12518)

17. Klein JT, Platt ML. 2013 Social information signaling by neurons in primate striatum. Curr. Biol. 23, 691-696. (doi:10.1016/j.cub.2013.03.022)

18. Noritake A, Ninomiya T, Isoda M. 2018 Social reward monitoring and valuation in the macaque brain. Nat. Neurosci. 21, 1452-1462. (doi:10.1038/s41593-018-0229-7)

19. Olsson A, Knapska E, Lindström B. 2020 The neural and computational systems of social learning. Nat. Rev. Neurosci. 21, 197-212. (doi:10.1038/s41583-020-0276-4)

20. Monier M, Nöbel S, Danchin E, Isabel G. 2019 Dopamine and serotonin are both 
required for mate-copying in Drosophila melanogaster. Front. Bebav. Neurosci. 12, 1-5. (doi:10.3389/fnbeh.2018.00334)

21. Kacsoh BZ, Bozler J, Ramaswami M, Bosco G. 2015 Social communication of predatorinduced changes in Drosophila behavior and germ line physiology. Elife 4, e07423. (doi:10.7554/eLife.07423)

22. Carcea I, Froemke RC. 2019 Biological mechanisms for observational learning. Curr. Opin. Neurobiol. 54, 178-185. (doi:10.1016/j.conb.2018.11.008)

23. Lindström B, Haaker J, Olsson A. 2018 A common neural network differentially mediates direct and social fear learning. Neuroimage 167, 121-129.

(doi:10.1016/j.neuroimage.2017.11.039)

24. Danchin É et al. 2019 Cultural flies: Conformist social learning in fruitflies predicts longlasting mate-choice traditions. Science (80-. ). 362, 1025-1030.

25. Fischer A. 2014 Epigenetic memory: The Lamarckian brain. EMBO J. 33, 945-967. (doi:10.1002/embj.201387637)

26. Campanelli SE, da Rocha JM, Oliveira JIN. 2019 Molecular and epigenetic mechanisms associated with extinction of fear memory: A systematic review. eNeurobiología 10.

27. Miller CA, Sweatt JD. 2007 Covalent modification of DNA regulates memory formation. Neuron 53, 857-869. (doi:10.1016/j.neuron.2007.02.022)

28. Lind J, Ghirlanda S, Enquist M. 2019 Social learning through associative processes: A computational theory. $R$. Soc. Open Sci. 6. (doi:10.1098/rsos.181777)

29. Worden BD, Papaj DR. 2005 Flower choice copying in bumblebees. Biol. Lett. 1, 504507. (doi:10.1098/rsbl.2005.0368)

30. Leadbeater E, Dawson EH. 2017 A social insect perspective on the evolution of social learning mechanisms. Proc. Natl. Acad. Sci. U. S. A. 114, 7838-7845.

(doi:10.1073/pnas.1620744114)

31. Dawson EH, Avarguès-Weber A, Chittka L, Leadbeater E. 2013 Learning by observation emerges from simple associations in an insect model. Curr. Biol. 23, 727-730. (doi:10.1016/j.cub.2013.03.035)

32. Dunlap AS, Nielsen ME, Dornhaus A, Papaj DR. 2016 Foraging Bumble Bees Weigh the Reliability of Personal and Social Information. Curr. Biol. 26, 1195-1199. (doi:10.1016/j.cub.2016.03.009)

33. Dawson EH, Chittka L. 2012 Conspecific and heterospecific information use in bumblebees. PLoS One 7, 1-6. (doi:10.1371/journal.pone.0031444)

34. Fogarty L, Creanza N, Feldman MW. 2015 Cultural Evolutionary Perspectives on Creativity and Human Innovation. Trends Ecol. Evol. 30, 736-754. (doi:10.1016/j.tree.2015.10.004)

35. Reader SM, Laland KN, editors. 2003 Animal innovation. Oxford University Press.

36. Dean LG, Vale GL, Laland KN, Flynn E, Kendal RL. 2014 Human cumulative culture: A comparative perspective. Biol. Rev. 89, 284-301. (doi:10.1111/brv.12053)

37. Enquist M, Ghirlanda S, Jarrick A, Wachtmeister CA. 2008 Why does human culture increase exponentially? Theor. Popul. Biol. 74, 46-55. (doi:10.1016/j.tpb.2008.04.007)

38. Alem S, Perry CJ, Zhu X, Loukola OJ, Ingraham T, Søvik E, Chittka L. 2016 Associative Mechanisms Allow for Social Learning and Cultural Transmission of String Pulling in an Insect. PLoS Biol. 14, 1-28. (doi:10.1371/journal.pbio.1002564)

39. Griffin AS, Guez D. 2014 Innovation and problem solving: A review of common 
mechanisms. Behav. Processes 109, 121-134. (doi:10.1016/j.beproc.2014.08.027)

40. Griffin AS, Diquelou M, Perea M. 2014 Innovative problem solving in birds: A key role of motor diversity. Anim. Behav. 92, 221-227. (doi:10.1016/j.anbehav.2014.04.009)

41. Day RL, Coe RL, Kendal JR, Laland KN. 2003 Neophilia, innovation and social learning: A study of intergeneric differences in callitrichid monkeys. Anim. Behav. 65, 559-571. (doi:10.1006/anbe.2003.2074)

42. Reader SM, Morand-Ferron J, Flynn E. 2016 Animal and human innovation: Novel problems and novel solutions. Philos. Trans. R. Soc. B Biol. Sci. 371.

(doi:10.1098/rstb.2015.0182)

43. Lefebvre L, Whittle P, Lascaris E, Finkelstein A. 1997 Feeding innovations and forebrain size in birds. Anim. Behavio, 549-560.

44. Reader SM, Laland KN. 2002 Social intelligence, innovation, and enhanced brain size in primates. Proc. Natl. Acad. Sci. U. S. A. 99, 4436-4441. (doi:10.1073/pnas.062041299)

45. Fiorito G, Scotto P. 1992 Observational learning in Octopus vulgaris. Science (80-. ). 256, 545-547.

46. Wilkinson A, Kuenstner K, Mueller J, Huber L. 2010 Social learning in a non-social reptile (Geochelone carbonaria). Biol. Lett. 6, 614-616. (doi:10.1098/rsbl.2010.0092)

47. Van Schaik CP, Deaner RO, Merrill MY. 1999 The conditions for tool use in primates: Implications for the evolution of material culture. J. Hum. Evol. 36, 719-741. (doi:10.1006/jhev.1999.0304)

48. Flynn E, Whiten A. 2010 Studying children's social learning experimentally 'in the wild'. Learn. Behav. 38, 284-296. (doi:10.3758/LB.38.3.284)

49. Derex M, Beugin MP, Godelle B, Raymond M. 2013 Experimental evidence for the influence of group size on cultural complexity. Nature 503, 389-391.

(doi:10.1038/nature12774)

50. Enquist M, Strimling P, Eriksson K, Laland K, Sjostrand J. 2010 One cultural parent makes no culture. Anim. Behav. 79, 1353-1362. (doi:10.1016/j.anbehav.2010.03.009)

51. Whiten A. 2019 Cultural evolution in animals. Annu. Rev. Ecol. Evol. Syst. 50, 27-48. (doi:10.1146/annurev-ecolsys-110218-025040)

52. Mesoudi A, Thornton A. 2018 What is cumulative cultural evolution? Proc. R. Soc. BBiological Sci. 285, 20180712.

53. Claidière N, Smith K, Kirby S, Fagot J. 2014 Cultural evolution of systematically structured behaviour in a non-human primate. Proc. R. Soc. B Biol. Sci. 281, 1-9.

(doi:10.1098/rspb.2014.1541)

54. Sasaki T, Biro D. 2017 Cumulative culture can emerge from collective intelligence in animal groups. Nat. Commun. 8, 1-6. (doi:10.1038/ncomms15049)

55. Jesmer BR et al. 2018 Is ungulate migration culturally transmitted? Evidence of social learning from translocated animals. Science (80-. ). 361, 1023-1025. (doi:10.1126/science.aat0985)

56. Tennie C, Call J, Tomasello M. 2009 Ratcheting up the ratchet: On the evolution of cumulative culture. Pbilos. Trans. R. Soc. B Biol. Sci. 364, 2405-2415. (doi:10.1098/rstb.2009.0052)

57. Vale GL, Flynn EG, Kendal RL. 2012 Cumulative culture and future thinking: Is mental time travel a prerequisite to cumulative cultural evolution? Learn. Motiv. 43, 220-230. (doi:10.1016/j.lmot.2012.05.010) 
58. Shea N, Boldt A, Bang D, Yeung N, Heyes C, Frith CD. 2014 Supra-personal cognitive control and metacognition. Trends Cogn. Sci. 18, 186-193.

(doi:10.1016/j.tics.2014.01.006)

59. Dean LG, Kendal RL, Schapiro SJ, Thierry B, Laland KN. 2012 Identification of the social and cognitive processes underlying human cumulative culture. Science (80-. ). 335, 1114-1118. (doi:10.1126/science.1213969)

60. Lewis HM, Laland KN. 2012 Transmission fidelity is the key to the build-up of cumulative culture. Philos. Trans. R. Soc. B Biol. Sci. 367, 2171-2180. (doi:10.1098/rstb.2012.0119)

61. Muthukrishna M, Shulman BW, Vasilescu V, Henrich J. 2014 Sociality influences cultural complexity. Proc. R. Soc. B 281, 20132511.

62. Stout D, Hecht EE. 2017 Evolutionary neuroscience of cumulative culture. Proc. Natl. Acad. Sci. U. S. A. 114, 7861-7868. (doi:10.1073/pnas.1620738114)

63. Davis SJ, Vale GL, Schapiro SJ, Lambeth SP, Whiten A. 2016 Foundations of cumulative culture in apes: Improved foraging efficiency through relinquishing and combining witnessed behaviours in chimpanzees (Pan troglodytes). Sci. Rep. 6, 1-12. (doi:10.1038/srep35953)

64. Pryluk R, Kfir Y, Gelbard-Sagiv H, Fried I, Paz R. 2019 A Tradeoff in the Neural Code across Regions and Species. Cell 176, 597-609.e18. (doi:10.1016/j.cell.2018.12.032)

65. Herculano-Houzel S. 2016 The human advantage: A new understanding of how our brain became remarkable. MIT Press.

66. Kaas JH, Herculano-Houzel S. 2017 What Makes the Human Brain Special: Key Features of Brain and Neocortex. In The physics of the mind and brain disorders (eds I Opris, MF Casanova), pp. 3-22. Springer International Publishing. (doi:10.1007/978-3-31929674-6_1)

67. Roberts WA. 2002 Are animals stuck in time? Psychol. Bull. 128, 473-489. (doi:10.1037/0033-2909.128.3.473)

68. Stout D. 2005 The social and cultural conext of stone-knapping skill acquisition. In Stone knapping: the necessary conditions for a uniquely hominin behaviour (eds B Brill, V Roux), pp. 331-340. McDonald Institute for Archaeological Research.

69. Walker R, Hill K, Kaplan H, McMillan G. 2002 Age-dependency in hunting ability among the Ache of eastern Paraguay. J. Hum. Evol. 42, 639-657.

(doi:10.1006/jhev.2001.0541)

70. Van Leeuwen EJC, Call J, Haun DBM. 2014 Human children rely more on social information than chimpanzees do. Biol. Lett. 10. (doi:10.1098/rsbl.2014.0487)

71. Tennie C, Call J, Tomasello M. 2010 Evidence for emulation in chimpanzees in social settings using the floating peanut task. PLoS One 5. (doi:10.1371/journal.pone.0010544)

72. Nielsen M. 2013 Young children's imitative and innovative behaviour on the floating object task. Infant Child Dev. 22, 44-52.

73. Beck SR, Apperly IA, Chappell J, Guthrie C, Cutting N. 2011 Making tools isn't child's play. Cognition 119, 301-306. (doi:10.1016/j.cognition.2011.01.003)

74. Dunstone J, Caldwell CA. 2018 Cumulative culture and explicit metacognition: A review of theories, evidence and key predictions. Palgrave Commun. 4, 1-11. (doi:10.1057/s41599-018-0200-y)

75. Scott-Phillips TC. 2015 Meaning in animal and human communication. Anim. Cogn. 18, 
801-805. (doi:10.1007/s10071-015-0845-5)

76. Scott-Phillips T. 2015 Speaking our minds. Palgrave Macmillan.

77. Csibra G. 2009 Natural pedagogy. Trends Cogn. Sci. 13, 148-153. (doi:10.1016/j.tics.2009.01.005)

78. Sperber D, Wilson D. 2002 Pragmatics, modularity and mind-reading. Mind Lang. 17, 323.

79. Senju A, Csibra G. 2008 Gaze Following in Human Infants Depends on Communicative Signals. Curr. Biol. 18, 668-671. (doi:10.1016/j.cub.2008.03.059)

80. Behne T, Carpenter M, Tomasello M. 2005 One-year-olds comprehend the communicative intentions behind gestures in a hiding game. Dev. Sci. 8, 492-499. (doi:10.1111/j.1467-7687.2005.00440.x)

81. Grosse G, Moll H, Tomasello M. 2010 21-Month-olds understand the cooperative logic of requests. J. Pragmat. 42, 3377-3383. (doi:10.1016/j.pragma.2010.05.005)

82. Schulze C, Tomasello M. 2015 18-month-olds comprehend indirect communicative acts. Cognition 136, 91-98. (doi:10.1016/j.cognition.2014.11.036)

83. Tauzin T, Gergely G. 2018 Communicative mind-reading in preverbal infants. Sci. Rep. 8. (doi:10.1038/s41598-018-27804-4)

84. Grosse G, Behne T, Carpenter M, Tomasello M. 2014 Infants communicate in order to be understood. Dev. Psychol. 46, 1710-1722. (doi:10.1037/a0020727)

85. Dingemanse $\mathbf{M}$ et al. 2015 Universal principles in the repair of communication problems. PLoS One 10, 1-15. (doi:10.1371/journal.pone.0136100)

86. Morin O. 2013 What does communication contribute to cultural transmission? Soc. Anthropol. 21, 230-235. (doi:10.1111/1469-8676.12014)

87. Henrich J. 2004 Demography and cultural evolution: How adaptive cultural processes can produce maladaptive losses - the Tasmania case. Am. Antiq. 69, 197-214.

88. Derex M, Boyd R. 2016 Partial connectivity increases cultural accumulation within groups. Proc. Natl. Acad. Sci. , 201518798. (doi:10.1073/pnas.1518798113)

89. Creanza N, Kolodny O, Feldman MW. 2017 Greater than the sum of its parts? Modelling population contact and interaction of cultural repertoires. J. R. Soc. Interface 14. (doi:10.1098/rsif.2017.0171)

90. Derex M, Mesoudi A. 2020 Cumulative cultural evolution within evolving population structures. Trends Cogn. Sci. 24, 654-667. (doi:10.1016/j.tics.2020.04.005)

91. Henrich J. 2009 The Evolution of Innovation-Enhancing Institutions. In Innovation in Cultural Systems: Contributions in Evolution Anthropology (eds SJ Shennan, MJ O’ Brien), Cambridge: MIT Press.

92. Migliano AB et al. 2017 Characterization of hunter-gatherer networks and implications for cumulative culture. Nat. Hum. Behav. 1, 1-6. (doi:10.1038/s41562-016-0043)

93. Centola D, Gonzlez-Avella JC, Eguíluz VM, San Miguel M. 2007 Homophily, cultural drift, and the co-evolution of cultural groups. J. Conflict Resolut. 51, 905-929. (doi:10.1177/0022002707307632)

94. Apicella CL, Marlowe FW, Fowler JH, Christakis NA. 2012 Social networks and cooperation in hunter-gatherers. Nature 481, 497-501. (doi:10.1038/nature10736)

95. Derex M, Godelle B, Raymond M. 2014 How does competition affect the transmission of information? Evol. Hum. Behav. 35, 89-95. (doi:10.1016/j.evolhumbehav.2013.11.001)

96. Henrich J. 2004 Cultural group selection, coevolutionary processes and large-scale 
cooperation. J. Econ. Behav. Organ. 53, 3-35. (doi:10.1016/S0167-2681(03)00094-5)

97. Sperber D. 1996 Explaining culture: A naturalistic approach. Oxford, UK: Blackwell Publishers Ltd.

98. Morin O. 2016 How traditions live and die. New York: Oxford University Press.

99. Knight J. 1992 Institutions and social conflict. Cambridge, UK: Cambridge University Press.

100. North DC. 1990 Institutions, institutional change, and economic performance. New York, NY: Cambridge University Press.

101. Ostrom E. 1990 Governing the commons: The evolution of institutions for collective action. Cambridge, UK: Cambridge University Press.

102. Nieder A. 2020 Neural constraints on human number concepts. Curr. Opin. Neurobiol. 60, 28-36. (doi:10.1016/j.conb.2019.10.003)

103. Epps P, Bowern C, Hansen CA, Hill JH, Zentz J. 2013 On numeral complexity in hunter-gatherer languages. Linguist. Typology 16. (doi:10.1515/lity-2012-0002)

104. Bloom P. 2004 Descartes' baby: How the science of child development explains what makes us buman. New York, NY: Basic Books.

105. Kuhlmeier VA, Bloom P, Wynn K. 2004 Do 5-month-old infants see humans as material objects? Cognition 94, 95-103. (doi:10.1016/j.cognition.2004.02.007)

106. Chudek M, McNamara R, Birch S, Bloom P, Henrich J. 2013 Developmental and crosscultural evidence for intuitive dualism. Psychol. Sci.

107. Jack AI. 2014 A scientific case for conceptual dualism: The problem of consciousness and the opposing domains hypothesis. In Oxford Studies in Experimental Philosophy (Vol. 1),

108. Pearce MT, Zaidel DW, Vartanian O, Skov M, Leder H, Chatterjee A, Nadal M. 2016 Neuroaesthetics: The Cognitive Neuroscience of Aesthetic Experience. Perspect. Psychol. Sci. 11, 265-279. (doi:10.1177/1745691615621274)

109. Sperber D, Hirschfeld LA. 2004 The cognitive foundations of cultural stability and diversity. Trends Cogn. Sci. 8, 40-46. (doi:10.1016/j.tics.2003.11.002)

110. Boyer P. 2001 Religion explained: The evolutionary origins of religious thought. New York: Basic Books.

111. Acerbi A. 2020 Cultural evolution in the digital age. Oxford University Press.

112. Miton H, Claidière N, Mercier H. 2015 Universal cognitive mechanisms explain the cultural success of bloodletting. Evol. Hum. Behav. 36, 303-312.

(doi:10.1016/j.evolhumbehav.2015.01.003)

113. Morin O. 2013 How portraits turned their eyes upon us: Visual preferences and demographic change in cultural evolution. Evol. Hum. Behav. 34, 222-229. (doi:10.1016/j.evolhumbehav.2013.01.004)

114. Boyer P. 2020 Why divination? Evolved psychology and strategic interaction in the production of truth. Curr. Anthropol. 61, 100-123. (doi:10.1086/706879)

115. Barrett JL. 2000 Exploring the natural foundations of religion. Trends Cogn. Sci. 4, 29-34.

116. Boyer P, Petersen MB. 2018 Folk-Economic Beliefs: An Evolutionary Cognitive Model. Behav. Brain Sci. , e158. (doi:10.1017/S0140525X17001960)

117. Singh M. 2019 The sympathetic plot, its psychological origins, and implications for the evolution of fiction. PsyArxiv , 1-28. (doi:10.31219/osf.io/p8q7a)

118. Tan ES. 1996 Emotion and the structure of narrative film: Film as an emotion machine. Mahwah, NJ: Lawrence Erlbaum Associates. 
119. Hogan PC. 2003 The mind and its stories: Narrative universals and human emotion. New York: Cambridge University Press.

120. Singh M. In press. Magic, explanations, and evil: On the origins and design of witches and sorcerers. Curr. Anthropol.

121. Singh M. 2018 The cultural evolution of shamanism. Bebav. Brain Sci. 41, e66. (doi:10.1017/S0140525X17001893)

122. Bebbington K, MacLeod C, Ellison TM, Fay N. 2017 The sky is falling: evidence of a negativity bias in the social transmission of information. Evol. Hum. Behav. 38, 92-101. (doi:10.1016/j.evolhumbehav.2016.07.004)

123. Blaine T, Boyer P. 2018 Origins of sinister rumors: A preference for threat-related material in the supply and demand of information. Evol. Hum. Behav. 39, 67-75. (doi:10.1016/j.evolhumbehav.2017.10.001)

124. Eriksson K, Coultas JC. 2014 Corpses, maggots, poodles and rats: Emotional selection operating in three phases of cultural transmission of urban legends. J. Cogn. Cult. 14, 126. (doi:10.1163/15685373-12342107)

125. Mesoudi A, Whiten A, Dunbar R. 2006 A bias for social information in human cultural transmission. Br. J. Psychol. 97, 405-431. (doi:10.1348/000712605X85871)

126. Stubbersfield JM, Tehrani JJ, Flynn EG. 2015 Serial killers, spiders and cybersex: Social and survival information bias in the transmission of urban legends. Br. J. Psychol. 106, 288-307. (doi:10.1111/bjop.12073)

127. Hester JB, Gibson R. 2003 The economy and second-level agenda setting: A time-series analysis of econom... Journal. Mass Commun. Q. 80.

128. Niven D. 2001 Bias in the news: Partisanship and negativity in media coverage of presidents George Bush and Bill Clinton. Harvard Int. J. Press. 6, 31-46.

129. Morin O, Acerbi A. 2017 Birth of the cool: a two-centuries decline in emotional expression in Anglophone fiction. Cogn. Emot. 31, 1663-1675. (doi:10.1080/02699931.2016.1260528)

130. Clasen M. 2017 Why horror seduces. Oxford University Press.

131. Morin O, Acerbi A, Sobchuk O. 2019 Why people die in novels: testing the ordeal simulation hypothesis. Palgrave Commun. 5, 1-10. (doi:10.1057/s41599-019-0267-0)

132. Acerbi A. 2019 Cognitive attraction and online misinformation. Palgrave Commun. 5, 17. (doi:10.1057/s41599-019-0224-y)

133. Rogers E. 2003 The diffusion of innovations. New York: The Free Press.

134. Singh M. 2020 Subjective selection and the evolution of complex culture. PsyArxiv (doi:10.31234/osf.io/4t2ud)

135. Thaler R, Sunstein C. 2004 Market efficiency and rationality: The peculiar case of baseball. Mich. Law Rev. 102, 1390-1403. (doi:10.2307/4141950)

136. Nemeroff C, Rozin P. 2000 The makings of the magical mind: The nature and function of sympathetical magical thinking. In Imagining the impossible: Magical, scientific, and religious thinking in children, pp. 1-34. (doi:10.1017/CBO9780511571381.002)

137. Vyse S. 2014 Believing in magic: The psychology of superstition. Oxford and New York: Oxford University Press.

138. Keltner D, Gruenfeld DH, Anderson C. 2003 Power, approach, and inhibition. Psychol. Rev. 110, 265-284. (doi:10.1037/0033-295X.110.2.265)

139. Singh M, Wrangham RW, Glowacki L. 2017 Self-interest and the design of rules. Hum. 
Nat. 28, 457-480. (doi:10.1007/s12110-017-9298-7)

140. Singh M, Glowacki L, Wrangham RW. 2016 Self-interested agents create, maintain, and modify group-functional culture. Behav. Brain Sci. 39, e30, 40-41. (doi:10.1017/S0140525X15000242)

141. Goldman I. 1955 Status rivalry and cultural evolution in Polynesia. Am. Anthropol. 57, 680-697. (doi:10.1525/aa.1955.57.4.02a00030)

142. Acemoglu D, Robinson JA. 2012 Why nations fail: The origins of power, prosperity, and poverty. New York, NY: Random House.

143. Baumard N, Chevallier C. 2015 The nature and dynamics of world religions: a life-history approach. Proc. R. Soc. B Biol. Sci. 282, 20151593. (doi:10.1098/rspb.2015.1593)

144. Watts J, Sheehan O, Atkinson QD, Bulbulia J, Gray RD. 2016 Ritual human sacrifice promoted and sustained the evolution of stratified societies. Nature , 1-7. (doi:10.1038/nature17159)

145. Henrich J, Boyd R. 2008 Division of labor, economic specialization, and the evolution of social stratification. Curr. Antbropol. 49, 715-724. (doi:10.1086/587889)

146. Matsa DA. 2011 Competition and product quality in the supermarket industry. Q.J. Econ. 126, 1539-1591. (doi:10.1093/qje/qjr031)

147. Olivares M, Cachon GP. 2009 Competing retailers and inventory: An empirical investigation of General Motors' dealerships in isolated U.S. markets. Manage. Sci. 9, 1586-1604. (doi:10.1287/mnsc.1090.1050)

148. Blake KR, Bastian B, Denson TF, Grosjean P, Brooks RC. 2018 Income inequality not gender inequality positively covaries with female sexualization on social media. Proc. Natl. Acad. Sci. 115, 8722-8727. (doi:10.1073/pnas.1717959115)

149. Piddocke S. 1965 The potlatch system of the southern Kwakiutl: A new perspective. Southwest. J. Anthropol. 21, 244-264.

150. De Freitas J, Thomas K, DeScioli P, Pinker S. 2019 Common knowledge, coordination, and strategic mentalizing in human social life. Proc. Natl. Acad. Sci. U. S. A. 116, 1375113758. (doi:10.1073/pnas.1905518116)

151. Prentice DA, Miller DT. 1993 Pluralistic ignorance and alcohol use on campus: Some consequences of misperceiving the social norm. J. Pers. Soc. Psychol. 64, 243-256. (doi:10.1037/0022-3514.64.2.243)

152. Bursztyn L, Gonzzlez A, Yanagizawa-Drott D. 2018 Misperceived Social Norms: Female Labor Force Participation in Saudi Arabia. SSRN Electron. J. (doi:10.2139/ssrn.3202392)

153. Lieberman DE. 2013 The story of the human body: Evolution, health, and disease. New York: Pantheon Books. 